\title{
Assessing Students' Understanding of the Measures of Central Tendency and Attitude towards Statistics in Rural Secondary Schools
}

\author{
Siti Shahirah Saidi ${ }^{1}$, Nyet Moi Siew ${ }^{1 *}$ \\ ${ }^{1}$ Universiti Malaysia Sabah, MALAYSIA \\ *CORRESPONDENCE: $\triangle$ snyetmoi@yahoo.com
}

\begin{abstract}
This research was conducted to assess the level of students' understanding of the measures of central tendency and attitude towards statistics. A survey research was conducted on Tenth Graders in nine secondary rural schools in Sabah, Malaysia. A total of 148 students were sampled using stratified random sampling. Statistical Understanding Test of the Measures of Central Tendency and Survey Attitude towards Statistics questionnaire were used as data collection tools. The data was analyzed descriptively and inferentially by using SPSS version 20.0. The results revealed that students' understanding of measures of central tendency was at a moderate level, while their attitude towards statistics was positive. Gender difference was found to be significant in students' understanding of measures of central tendency $(p=0.032)$, but not in their attitude towards statistics. Generally, male students had a higher understanding than the female students. Furthermore, there were no significant relationships between students' understanding of measures of central tendency and attitude towards statistics, except for Effort component ( $r=-$ $0.299, p<.05)$. The finding showed that students who willingly put a great effort to learn statistics did not necessarily warrant a good understanding of the measures of central tendency. This study implied that Mathematics educators should remind students that the quality of learning with the appropriate learning technique invested in it would warrant better understanding of the measures of central tendency.
\end{abstract}

Keywords: understanding of measures of central tendency, attitude towards statistics, rural school, tenth graders

\section{INTRODUCTION}

Statistics has always been perceived as one of the most challenging subject areas among school students. According to Garfield and Ben-Zvi (2008), statistics is considered as a difficult subject to learn due to the complexity of statistical concepts. Understanding of statistical concepts is different from understanding the mechanics of statistics which involves plugging numbers into the correct formula. Students who can understand the statistical concepts have the ability to read and use tools such as percentage, ratio, measures of spread, central tendency and variability, as well as tables, graphs and maps (Australian Bureau of Statistics, n.d.).

Among the statistical concepts that students often have difficulty learning is the measures of central tendency concept. The measures of central tendency is one of the statistical concepts in the descriptive statistics, along with the measure of variability, which consists of mean, mode, and median. Research on

Article History: Received 11 July $2018 \bullet$ Revised 21 October $2018 \bullet$ Accepted 2 November 2018

(C) 2019 by the authors; licensee Modestum Ltd., UK. Open Access terms of the Creative Commons Attribution 4.0 International License (http://creativecommons.org/licenses/by/4.0/) apply. The license permits unrestricted use, distribution, and reproduction in any medium, on the condition that users give exact credit to the original author(s) and the source, provide a link to the Creative Commons license, and indicate if they made any changes. 
students' understanding of measures of central tendency has been done extensively by previous researchers (Broers \& Imbos, 2005; Ismail \& Shiau, 2015; Ramsey, 1990; Reston \& Idris, 2014). Most of the studies focused on the students' understanding of mean, and only several researches have focused on the students' understanding of mode and median. A significant amount of past studies also revealed that students focused too much on mastering the computational part and memorizing the formula for them to answer statistical questions. However, their understanding towards the mean concept is found to be lacking, since many students have difficulties in explaining this concept. Woldemicheal (2015) further elaborates that the abstractness of the statistical concepts of the measures of central tendency contributed to difficulties in students' understanding.

One of the goal of statistics education is to encourage a positive attitude towards statistics, besides to improve students' ability of understanding of statistics (Liau, Kiat \& Nie, 2015). A positive attitude towards learning is important to master the core content of the subject matters under study (Ghulami, Ab Hamid, \& Zakaria, 2015). In tandem, statistics educators believe that attitudes toward statistics are important in the process of learning (Mahmud, 2010). Ashaari, Mohamed, and Tengku Wook (2011) reinforces the importance of assessing students' attitudes towards statistics in order to encourage the students to understand the statistics concept, improve their skills in statistics and to appreciate the knowledge in their daily lives. Students who have a negative attitude towards this subject will have difficulty in learning the course effectively.

Under the Malaysian Primary School Standard Mathematics Curriculum, the concept of the measures of central tendency is introduced to students when they are in Fifth Grade (Curriculum Development Division, 2014), where they are guided on how to identify mode, median, mean, and range from the given data and taught to determine these measures for sets with up to 10 data values. During Ninth Grade, the students are guided on how to use the mode, median, and mean concepts to solve problems (Curriculum Development Division, 2011). Meanwhile, during Tenth Grade, students are taught the ways of understanding and using mode, median, and mean concepts for grouped data (Curriculum Development Division, 2012).

However, there is little evidence to indicate research conducted to investigate students' understanding of the measures of central tendency and attitudes towards statistics in Malaysian schools. In a comparative study which evaluated Fourth Grade students' achievements in mathematics between urban and rural schools in Sabah, Malaysia, it was discovered that students in urban schools outperformed their peers in rural schools (Singh et al., 2010). In an affiliated research conducted on 160 Tenth Grade students in Kuching, Malaysia, students were discovered to having positive attitudes toward mathematics (Chua, 2009). As these studies measured just achievement in mathematics and attitudes toward mathematics, a crucial question was raised: How will secondary school students perform in an assessment of their understanding of the measures of central tendency and attitudes towards statistics? There are relatively few published studies specifically geared towards rural secondary school students. Sabah, an East Malaysian state with a relatively high proportion of students in rural schools. According to the Sabah Economic Development and Investment Authority Blueprint (SDC, 2011), 72\% of Sabah's schools were located in rural areas. In terms of infrastructure, most rural secondary schools in Sabah lack access to good teaching and learning resources. These limited opportunities and facilities have somewhat created a gap in education attainment between rural and urban schools in Sabah and in Malaysia as a whole. Thus, further research needs to be undertaken with a broader scope that focuses on secondary school students in rural schools and assess more specifically, their level of understanding of the measures of central tendency and attitudes towards statistics.

\section{LITERATURE REVIEW}

\section{Students' Understanding of Statistical Concepts}

According to Batanero, Merino, and Díaz (2003), students' understanding of statistical concepts can be assessed and distinguished into five interrelated components, which are students' understanding of problems from which the concept has emerged, representation of the concept, procedures and algorithm, definition and properties, and arguments and proofs. For example, in the case of the mean concept, one of the present problems is to find the best representative value or finding the best estimation of an unknown quantity $(X)$ when several different measurements $X_{1}, X_{2}, \ldots X_{n}$ of the quantity are available. Meanwhile, the representation of the concept is related to the language used for the concept. For example, the term "average" or "expected value" is used for "mean". The procedures and algorithms on the other hand involve the computation of the mean, such as computing the mean from the raw data and frequency table. Definition and properties is related 
to the definition of the concept, and properties of the mean concept such as the effect of extreme values on the mean, or the relative position of mean in an asymmetrical distribution. The arguments and proof component is used to convince others of the methods used in solving the problems.

Earlier studies have reported that students faced difficulties in understanding the concept of the measures of central tendency. For example, in a study which assessed 123 middle school students' understanding of the concept of arithmetic average, Cai and Moyer (1995) found students faced difficulties in explaining their answers, indicating students lack conceptual understanding of the arithmetic average. An affiliated research conducted on 412 Tenth Grade Malaysian students found that students held a lot of misconceptions when computing the mean, mode, and median data from a histogram (Ismail \& Shiau, 2015). However, there is negligible empirical support concerning students' difficulty in understanding of measures of central tendency in Malaysian secondary schools.

Gender difference in students' understanding of measures of central tendency has rarely been reported in previous studies, and to date, very few literatures exist. Batanero et al. (2003) in their study found that there was no significant difference in students' understanding of average data based on gender. On the other hand, Tempelaar (2004) found that there was a significant difference in students' understanding of measures of central tendency based on gender among the first-year Economics and Business students who took the Quantitative Method course. These contradictory results raised a question: Does gender affect the understanding of measures of central tendency among rural Malaysian school students?

\section{Students' Attitude towards Statistics}

Schau (2003) categorized students' attitude towards statistics into six components, which are Affect, Value, Cognitive Competence, Difficulty, Effort and Interest. Affect refers to the student's feeling towards statistics, whether they have positive or negative feelings concerning statistics, while Value refers to the attitudes about the usefulness, relevance, and worth of statistics in personal and professional life. On the other hand, Cognitive Competence refers to the attitudes about intellectual knowledge and skills when applied to statistics, and Difficulty refers to the attitudes about the difficulty of statistics as a subject. Interest refers to the students' level of individual interest in statistics and Effort refers to the amount of effort students spend on learning statistics.

Meanwhile, Judi, Ashaari, Mohamed, and Wook (2011) in their study of students' profiles based on attitude towards statistics explained that the students' attitude towards statistics is divided into two categories, either positive or negative. A positive attitude towards statistics could contribute to the students' achievement in statistics and enable students to develop statistical thinking skills, to apply knowledge acquired in everyday life. Meanwhile, a negative attitude towards statistics generally makes students lose focus in the class and lack interest in statistics.

Numerous studies found that students indicated a positive attitude toward statistics (Ashaari, Judi, Mohamed, \& Tengku Wook, 2012; Carmona, Martinez \& Sanchez, 2005; Ghulami et al., 2015; Griffith et al., 2012; Mahmud, 2010; Naccache, 2012; Stanisavljevic et al., 2014; Zhang et al., 2012). However, most of the Malaysian studies focused on undergraduate and postgraduate students who took the statistics course in their universities. Even on the global platform, researches on attitude towards statistics were mostly focused at the higher level of education. Schau, Millar and Petocz (2012) supported that all the studies that assessed students' attitudes focused on post-secondary students, usually at four-year and advanced degree granting institutions. Yet, little is known of the level of attitude towards statistics among secondary students in rural Malaysian schools.

Literature on gender differences in attitudes toward statistics reports contradictory results. Some authors reported that men expressed more positive attitudes towards statistics compared to women (e.g., Chiesi \& Prim, 2015; Tempelaar \& Nijhuis, 2007). Others found no gender differences (e.g., Judi, Ashaari, Mohamed, \& Wook, 2011; Martins, Nascimento, \& Estrada, 2011; Wisenbaker, Scott \& Nasser, 2000). Some others have reported more positive attitudes for women (e.g., Mahmud \& Zainol, 2008; Rhoads \& Hubele, 2000). Nonetheless, very few researches has been published on gender differences in attitudes toward statistics among Malaysian rural school students. 


\section{Relationship between Students’ Achievement in Statistics and Their Attitude towards Statistics}

Past studies revealed that there is a positive relationship between students' achievement in Statistics and their attitudes towards this subject. For instance, a study by Emmioglu and Capa-Aydin (2012) revealed that there is a consistent positive relationship between students' attitudes toward statistics and statistics achievement. Rosli and Maat (2017) also found a medium and positive relation between attitude towards statistics and performance among the post-graduates. Most of the previous studies were conducted on the students' attitude-achievement relationship, and this attitude variable also has been used by previous researchers to predict students' achievement. However, relatively little research is conducted on the relationship between students' understanding of the measures of central tendency and students' attitudes towards statistics in all levels of education, including secondary school students. Consequently, this study attempted to investigate whether there is a relationship between students' understanding of measures of central tendency and their attitudes towards statistics among secondary school students in rural schools.

\section{Influence of Students' Attitude towards Statistics on Understanding of Statistical Concepts}

Zhang et al. (2012) explained that students' attitudes towards statistics can directly influence their understanding of statistical concepts and methods. Besides that, the students' attitudes towards statistics also affects whether they will develop useful statistical thinking skills and apply statistics knowledge in their future professional careers. Students' attitudes about intellectual knowledge and skills applied to statistics (Cognitive Competence) have always been reported to have significant influence on the students' achievement in statistics by previous studies. For example, Naccache (2012) in her study of investigating the factors that influence students' performances in a statistics course in Lebanon, revealed that Cognitive Competence, Effort, and Affect components in Survey Attitude towards Statistics (SATS-36) influenced the students' achievement in their Statistics course. Meanwhile, Chiesi and Primi (2015) posit that Cognitive Competence, as well as Affect and mathematical knowledge could affect the psychology of students' achievements in statistics at the University of Florence in Italy. Milic, Masic, Milin-Lazovic, Trajkovic, Bukumiric, and Savic (2016)'s study on the other hand showed that the medical students' Cognitive Competence score in SATS-36 had significant influence with student' GPA (Grade Point Average). According to Mohamad Judi, Ashaari, Mohamed, and Tengku Wook (2011), students with positive attitudes towards statistics will be able to develop statistical thinking, use statistical knowledge to solve daily life problems, and have a desire to follow more advanced statistical courses in the future. Whereas, students with negative attitudes towards statistics will display anxiety towards statistics in the classroom. These findings raised another crucial question: Is attitude influential towards statistics on the understanding of the measures of central tendency among rural secondary school students?

\section{PURPOSE OF STUDY}

The purpose of this research was to assess the level of students' understanding of the measures of central tendency and attitudes towards statistics among secondary school students in rural schools. The research was also conducted to ascertain whether there was any significant difference in students' understanding of the measures of central tendency and attitudes towards statistics based on gender. Additionally, this research also aimed to establish whether there was significant relationship between students' attitudes towards statistics and students' understanding of the measures of central tendency, and influence of students' attitudes towards statistics on students' understanding of the measures of central tendency.

Regarding this research, an operational definition of understanding of the measures of central tendency refers to Definition, Properties, Problem and Representation, Procedure, and Argument and Proof about mean, mode and median data. Students' attitude towards statistics refers to Affect, Value, Cognitive Competence, Difficulty, Effort and Interest.

The research questions guiding this research were:

1. What is the level of students' understanding of the measures of central tendency?

2. What is the level of students' attitudes towards statistics?

3. Is there a difference in students' understanding of the measures of central tendency based on gender? 
Table 1. Revised Items in SATS Instrument

\begin{tabular}{lll}
\hline Item & Version & Statement of Item \\
\hline \multirow{2}{*}{1} & Original & I plan to complete all of my statistics assignments. \\
\cline { 2 - 3 } 2 & Revised & I plan to complete all of my statistics homeworks. \\
\cline { 2 - 3 } 11 & Original & I plan to work hard in my statistics course. \\
\hline \multirow{2}{*}{19} & Original & I plan to work hard in the topic of statistics \\
\cline { 2 - 3 } \multirow{2}{*}{ Revised } & I will have no idea of what's going on in this statistics course. \\
\cline { 2 - 3 } & Rriginal & I will enjoy taking statistics courses. \\
\hline
\end{tabular}

4. Is there a difference in students' attitudes towards statistics based on gender?

5. Is there a relationship between students' understanding of the measures of central tendency and students' attitudes towards statistics?

6. Is there an influence of students' attitudes towards statistics on students' understanding of measures of central tendency?

\section{METHODOLOGY}

In this study, a survey research design was used to obtain information regarding students' understanding of the measures of central tendency and attitude towards statistics. The formula of Krejcie and Morgan (1970) was adopted to determine the sample size of the study. This was to ensure that the results obtained from the samples could represent a large population. A total of 148 Tenth Grade Science Stream students were randomly selected from nine secondary schools in the Kota Belud district by using stratified random sampling, where the school is the strata. The selected schools are located within the Interior Division of Sabah, Malaysia. The schools are located about 75 kilometres from Kota Kinabalu. The participants consisted of 148 Tenth Grade Science Stream students with 97 females (65.5\%) and 51 males (34.5\%) aged 16 years old. In the Malaysian schooling system, students from the age of 16 have the opportunity to pursue two years of study in the upper secondary upon completion of the lower secondary education. Students who are academically inclined can choose between two main streams: Science or Arts. Seemingly, the Science Stream students are perceived to be more adept at performing in mathematics related subjects.

\section{Instrumentation}

Two instruments were used for this study in order to answer the research questions. Statistical Understanding Test of Measures of Central Tendency (SUTMCT) was used to assess students' understanding of the measures of central tendency. SUTMCT was developed by the researchers based on the theoretical model on the meaning/ understanding of mathematical/statistical concepts proposed by Godino and Batanero (1997), where the meaning of concept was distinguished into five interrelated components, which are students' understanding of the problem, representation, procedures, definition and properties, and argument and proof. SUTMCT consisted of 14 multiple-choice items and 4 subjective items focusing on mean, mode, and median.

The Survey Attitudes towards Statistics (SATS) questionnaire adapted from Schau (2003) was administered to assess students' attitude towards statistics. Some of the items were revised slightly so it can be understood by Malaysian Tenth Grade students (Table 1). SATS is a 7-point Likert type scale questionnaire form and has 36 items. The responses range from 1 (strongly disagree) through 4 (neither disagree nor agree) to 7 (strongly agree), where the higher scores correspond to a more positive attitude. Meanwhile, the negatively worded items are scored by reversing the numeric values. SATS contains six components, which were Cognitive Competence, Value, Affect, Difficulty, Effort and Interest.

A total of 30 students were randomly selected from a secondary school in Kota Belud, Sabah for the pilot study. The results of the analysis showed that the SUTMCT instrument had the Cronbach's alpha reliability coefficient of 0.765 , while the SATS instrument had the alpha reliability coefficient of 0.937. Both instruments were reliable within the Malaysian secondary school educational context.

\section{Data Analysis}

The analysis of the test and questionnaire was done by using "Statistical Package for Social Science (SPSS)" version 20.0. In this study, descriptive statistics and inferential statistics were used to analyze the 
Table 2. Descriptive Statistical Analysis for the Level of Students' Understanding of the Measures of Central Tendency $(\mathrm{n}=148)$

\begin{tabular}{ccccc}
\hline Level & Frequency & Percentage & $\boldsymbol{M}$ & SD \\
\hline Very High & 6 & 4.1 & & \\
High & 18 & 12.2 & 46.312 & 15.632 \\
Moderate & 76 & 51.4 & & \\
Low & 39 & 26.4 & & \\
Very Low & 9 & 6.1 & & \\
\hline Total & 148 & 100 &
\end{tabular}

Table 3. Level of Students' Understanding of the Measures of Central Tendency according to Constructs $(\mathrm{N}=148)$

\begin{tabular}{cccc}
\hline Understanding Construct & $\boldsymbol{M}$ & $\boldsymbol{S D}$ & Level \\
\hline Definition & 78.15 & 28.23 & High \\
Properties & 39.53 & 16.64 & Low \\
Problem and Representation & 9.46 & 22.85 & Very Low \\
Procedure & 56.02 & 24.69 & Moderate \\
Argument and Proof & 2.36 & 13.47 & Very Low \\
\hline
\end{tabular}

data and to answer the research questions. The students' level of understanding of the measures of central tendency was determined based on their marks (percentage, \%). Students' level of understanding was categorized into five levels based on categories suggested by Tarmimi and Kadri (2016), which are very high (80-100), high (60-79), moderate (40-59), low (20-39) and very low (0-19). Correct response will be given 1 mark, while 0 mark for incorrect response or no answer. Meanwhile, to determine the level of students' attitudes towards statistics, the mean score for each of the components in the SATS was calculated. The level of students' attitudes towards statistics was categorized into three levels, which are positive (4.50-7.00), neutral (3.514.49), and negative (0.00-3.50) attitude towards statistics, as interpreted in Mahmud (2010).

An independent Sample t-Test was used to identify the differences of students' understanding of the measures of central tendency and the students' attitudes towards statistics based on gender. Besides that, the Pearson Product Moment Correlation Coefficient was used to determine the relationship between the students' level understanding of the measures of central tendency and attitude towards statistics. On top of that, multiple linear regression analysis was also used to find the influence of students' attitude towards statistics on their understanding of measures of central tendency. To conduct multiple linear regression analysis, the components of students' attitudes towards statistics (Cognitive Competence, Value, Difficulty, Affect, Interest and Effort) were used as the predictor variables, while the students' level of understanding of measures of central tendency was the response.

\section{FINDINGS}

\section{Research Question 1}

The results from the descriptive statistics analysis in Table 2 shows that the level of students' understanding of the measures of central tendency were: 'Very High' level (4.1\%), 'High' level (12.2\%), 'Moderate' level (51.4\%), 'Low' level (26.4\%), and 'Very Low' level (6.1\%). Therefore, this shows that the students' understanding of the measures of central tendency was in the moderate level $(51.4 \%, M=46.31$, $S D=15.63)$. Table 3 shows the level of students' understanding of the measures of central tendency with respect to its constructs. As a conclusion, students had a high level of understanding regarding the definition; a moderate level of understanding regarding the procedure; a low level of understanding on properties; and a very low understanding on the problem and representation, as well as argument and proof.

\section{Research Question 2}

Overall, the result from the descriptive statistics analysis in Table 4 shows that the level of students' attitudes towards statistics among Tenth Grade students was found to be 'Positive'. Meanwhile, as for the attitude towards statistics components, students were found to hold a positive attitude for all of the components, except for the Value components, which was neutral. 
Table 4. Descriptive Statistical Analysis for the Level of Students' Attitude towards Statistics $(N=148)$

\begin{tabular}{cccc}
\hline Attitude Component & $\boldsymbol{M}$ & $\boldsymbol{S D}$ & Level \\
\hline Cognitive Competence & 4.704 & 1.102 & Positive \\
\hline Value & 4.488 & 0.754 & Neutral \\
\hline Difficulty & 4.617 & 0.871 & Positive \\
\hline Affect & 4.589 & 0.893 & Positive \\
\hline Interest & 4.698 & 1.075 & Positive \\
\hline Effort & 4.882 & 1.104 & Positive \\
\hline Overall & 4.627 & 0.734 & Positive
\end{tabular}

Table 5. Independent Sample T-Test Analysis for the Differences in Students' Understanding of the Measures of Central Tendency based on Gender

\begin{tabular}{ccccccc}
\hline Gender & $\boldsymbol{n}$ & $\boldsymbol{M}$ & $\boldsymbol{S D}$ & $\boldsymbol{t}$ & $\boldsymbol{d} \boldsymbol{f}$ & $\boldsymbol{p}$ \\
\hline Female & 97 & 44.072 & 13.105 & \multirow{2}{*}{-2.186} & \multirow{2}{*}{75.713} & \multirow{2}{*}{032} \\
Male & 51 & 50.571 & 18.985 & & \\
\hline
\end{tabular}

Table 6. Independent Sample t-Test Analysis for the Differences of Students' Understanding of the Measure of Central of Tendency Constructs based on Gender

\begin{tabular}{|c|c|c|c|c|c|c|c|}
\hline Construct & Gender & $n$ & $M$ & $S D$ & $t$ & $d f$ & $p$ \\
\hline Definition & $\begin{array}{c}\text { Female } \\
\text { Male }\end{array}$ & $\begin{array}{l}97 \\
51\end{array}$ & $\begin{array}{l}80.069 \\
74.510\end{array}$ & $\begin{array}{l}24.842 \\
33.723\end{array}$ & 1.038 & 79.241 & .302 \\
\hline Properties & $\begin{array}{c}\text { Female } \\
\text { Male }\end{array}$ & $\begin{array}{l}97 \\
51\end{array}$ & $\begin{array}{l}36.942 \\
44.444 \\
\end{array}$ & $\begin{array}{l}15.632 \\
17.533 \\
\end{array}$ & -2.660 & 146 & .009 \\
\hline $\begin{array}{c}\text { Problem and } \\
\text { Representation }\end{array}$ & $\begin{array}{c}\text { Female } \\
\text { Male }\end{array}$ & $\begin{array}{l}97 \\
51\end{array}$ & $\begin{array}{c}5.670 \\
16.667 \\
\end{array}$ & $\begin{array}{l}17.495 \\
29.439 \\
\end{array}$ & -2.450 & 69.051 & .017 \\
\hline Procedure & $\begin{array}{c}\text { Female } \\
\text { Male }\end{array}$ & $\begin{array}{l}97 \\
51\end{array}$ & $\begin{array}{l}53.046 \\
61.676 \\
\end{array}$ & $\begin{array}{l}22.904 \\
27.109 \\
\end{array}$ & -2.043 & 146 & .043 \\
\hline $\begin{array}{c}\text { Argument and } \\
\text { Proof }\end{array}$ & $\begin{array}{c}\text { Female } \\
\text { Male }\end{array}$ & $\begin{array}{l}97 \\
51\end{array}$ & $\begin{array}{l}0.516 \\
5.882 \\
\end{array}$ & $\begin{array}{c}5.077 \\
21.557 \\
\end{array}$ & -1.753 & 52.935 & .085 \\
\hline
\end{tabular}

\section{Research Question 3}

Based on Table 5, the result of the Independent Sample t-Test analysis shows that there was a significant difference in students' understanding of the measures of central tendency based on gender $(t=-2.186, d f=$ $75.713, p=.032)$. Generally, male students held a higher understanding of the measures of central tendency compared to the female students. Table 6 shows the result of analysis for the gender differences according to the constructs of understanding of measures of central tendency. The result shows that male students had a higher mean score in all the constructs except for the Definition construct. However, only Properties $(t=-2.660$, $d f=146, p=.009)$, Problem and Representation $(t=-2.450, d f=69.051, p=.017)$, and Procedure $(t=-2.043, d f=$ $146, p=.043)$ showed a significant difference based on gender.

\section{Research Question 4}

Based on the result in Table 7, the Independent Sample t-Test analysis showed that there was no significant difference in students' attitude towards statistics based on gender $(t=1.301, d f=146, p=.195)$. Similarly, the results of the Independent Sample t-Test analysis (Table 8) also shows there were no significant difference in students' attitude towards statistics components between female and male students. Even though the mean score showed that the female students exhibited a more positive attitude in all the attitude components compared to the male students, however, the differences were insignificant. 
Table 7. Independent Sample t-Test Analysis for the Differences in Students' Attitude towards Statistics based on Gender

\begin{tabular}{ccccccc}
\hline Gender & $\boldsymbol{n}$ & $\boldsymbol{M}$ & $\boldsymbol{S D}$ & $\boldsymbol{t}$ & $\boldsymbol{d} \boldsymbol{f}$ & $\boldsymbol{p}$ \\
\hline Female & 97 & 4.686 & 0.714 & \multirow{2}{*}{1.301} & \multirow{2}{*}{146} & \multirow{2}{*}{195} \\
Male & 51 & 4.516 & 0.828 & & \\
\hline
\end{tabular}

Table 8. Independent Sample t-Test Analysis for the Differences of Students' Attitudes towards Statistics Components based on Gender

\begin{tabular}{|c|c|c|c|c|c|c|c|}
\hline Component & Gender & $n$ & $M$ & $S D$ & $t$ & $d f$ & $p$ \\
\hline Cognitive & Female & 97 & 4.722 & 0.917 & \multirow{2}{*}{0.237} & \multirow{2}{*}{73.250} & \multirow{2}{*}{.813} \\
\hline Competence & Male & 51 & 4.670 & 1.398 & & & \\
\hline \multirow[t]{2}{*}{ Value } & Female & 97 & 4.551 & 0.734 & \multirow{2}{*}{1.405} & \multirow{2}{*}{146} & \multirow{2}{*}{.162} \\
\hline & Male & 51 & 4.368 & 0.786 & & & \\
\hline \multirow{2}{*}{ Difficulty } & Female & 97 & 4.691 & 0.758 & \multirow{2}{*}{1.297} & \multirow{2}{*}{78.256} & \multirow{2}{*}{.199} \\
\hline & Male & 51 & 4.477 & 1.047 & & & \\
\hline \multirow[t]{2}{*}{ Affect } & Female & 97 & 4.614 & 0.827 & \multirow{2}{*}{0.476} & \multirow{2}{*}{146} & \multirow{2}{*}{.635} \\
\hline & Male & 51 & 4.540 & 1.013 & & & \\
\hline \multirow{2}{*}{ Interest } & Female & 97 & 4.769 & 1.066 & \multirow{2}{*}{1.104} & \multirow{2}{*}{146} & \multirow{2}{*}{.272} \\
\hline & Male & 51 & 4.564 & 1.090 & & & \\
\hline \multirow{2}{*}{ Effort } & Female & 97 & 4.987 & 1.007 & \multirow{2}{*}{1.610} & \multirow{2}{*}{146} & \multirow{2}{*}{.109} \\
\hline & Male & 51 & 4.681 & 1.254 & & & \\
\hline
\end{tabular}

Table 9. Relationship between Students' Understanding of the Measures of Central Tendency and Students' Attitude towards Statistics

\begin{tabular}{ccc}
\hline & & $\begin{array}{c}\text { Students' Understanding of the } \\
\text { Measures of Central Tendency }\end{array}$ \\
\hline Students' Attitude towards & Pearson Correlation & -0.148 \\
Statistics & Sig. (2-tailed) & .072 \\
& $n$ & 148 \\
\hline
\end{tabular}

Table 10. Pearson Product Moment Correlation Coefficient Analysis ( $\mathrm{n}=148)$

\begin{tabular}{|c|c|c|}
\hline $\begin{array}{c}\text { Students' Attitude towards } \\
\text { Statistics Components }\end{array}$ & & $\begin{array}{l}\text { Students' Understanding of the } \\
\text { Measures of Central Tendency }\end{array}$ \\
\hline Cognitive Competence & $\begin{array}{l}\text { Pearson Correlation } \\
\text { Sig. (2-tailed) } \\
\end{array}$ & $\begin{array}{c}-0.038 \\
.645 \\
\end{array}$ \\
\hline Value & $\begin{array}{l}\text { Pearson Correlation } \\
\text { Sig. (2-tailed) }\end{array}$ & $\begin{array}{c}-0.134 \\
.104 \\
\end{array}$ \\
\hline Difficulty & $\begin{array}{l}\text { Pearson Correlation } \\
\text { Sig. (2-tailed) }\end{array}$ & $\begin{array}{c}-0.158 \\
.054 \\
\end{array}$ \\
\hline Affect & $\begin{array}{l}\text { Pearson Correlation } \\
\text { Sig. (2-tailed) } \\
\end{array}$ & $\begin{array}{c}-0.062 \\
.457 \\
\end{array}$ \\
\hline Interest & $\begin{array}{l}\text { Pearson Correlation } \\
\text { Sig. (2-tailed) } \\
\end{array}$ & $\begin{array}{c}-0.072 \\
.385 \\
\end{array}$ \\
\hline Effort & $\begin{array}{l}\text { Pearson Correlation } \\
\text { Sig. (2-tailed) } \\
\end{array}$ & $\begin{array}{l}-0.299 \\
<.05\end{array}$ \\
\hline
\end{tabular}

\section{Research Question 5}

Based on Table 9, the Pearson Product Moment Correlation Coefficient analysis shows that there were no significant and very weak negative relationship between students' understanding of the measures of central tendency and students' attitude towards statistics $(r=-0.148, p=.072)$. Meanwhile, Table 10 shows the relationship between students' understanding of the measures of central tendency and students' attitudes towards statistics components. The result shows that all the student's attitudes towards statistics components were very weakly correlated with the students' understanding of the measures of central tendency, and these correlations were not significant, except for the Effort component $(r=-0.299, p<.05)$. 
Table 11. Model Summary

\begin{tabular}{|c|c|c|c|c|c|}
\hline $\mathbf{R}$ & R Squar & & Adjusted R Square & \multicolumn{2}{|c|}{ Std. Error of the Estimate } \\
\hline 0.464 & 0.215 & & 0.182 & \multicolumn{2}{|c|}{14.137} \\
\hline Model & Sum of Squares & dff & Mean Square & $\mathbf{F}$ & Sig. \\
\hline $\begin{array}{c}\text { Regression } \\
\text { Residual } \\
\text { Total }\end{array}$ & $\begin{array}{c}7739.414 \\
28180.635 \\
35919.949\end{array}$ & $\begin{array}{c}6 \\
141 \\
147\end{array}$ & $\begin{array}{c}1289.886 \\
199.863\end{array}$ & 6.454 & $p<.05$ \\
\hline
\end{tabular}

Table 13. Multiple Linear Regression Analysis of Students' Attitudes towards Statistics on the Students' Understanding of the Measures of Central Tendency

\begin{tabular}{cccc}
\hline Predictor Variable & $\boldsymbol{\beta}$ & $\boldsymbol{t}$ & $\boldsymbol{p}$ \\
\hline Constant & 65.511 & 8.794 & $<.05$ \\
Cognitive Competence & 5.922 & 3.347 & 0.001 \\
Value & -1.290 & -0.542 & 0.589 \\
Difficulty & -5.166 & -2.740 & 0.007 \\
Affect & 3.429 & 1.567 & 0.119 \\
Interest & 2.459 & 1.383 & 0.169 \\
Effort & -9.566 & -5.640 & 0.000 \\
\hline
\end{tabular}

\section{Research Question 6}

Table 11, Table 12, and Table 13 shows the model summary, ANOVA table and Multiple Linear Regression analysis for the influence of students' attitudes towards statistics on students' understanding of the measures of central tendency respectively. The result from the multiple linear regression analysis shows that the regression model which consisted of Cognitive Competence, Value, Difficulty, Affect, Interest and Effort variables significantly explained the $21.5 \%\left(R^{2}=0.215\right)$ variability of the dependent (response) variable, which was students' understanding of the measures of central tendency $\left(F_{(6,141)}=6.454, p<.05\right)$. However, only Cognitive Competence $(B=5.922, t=3.347, p<0.05)$, Difficulty $(B=-5.166, t=-2.740, p<0.05)$, and Effort $(B=-9.566, t=-5.640, p<0.05)$ variables could predict the students' understanding of the measures of central tendency significantly. This indicates that these three attitude variables have significant influence on the students' understanding of the measures of central tendency. In general, the multiple linear regression model for the influence of the Cognitive Competence, Difficulty, and Effort towards statistics on the students' understanding of the measures of central tendency can be written as the following:

$$
Y=65.511+5.922 \text { Cognitive }-5.166 \text { Difficulty }-9.566 \text { Effort }
$$

On the other hand, the other three attitude variables (Value, Affect, and Interest) were not the predictors for the students' understanding of the measures of central tendency, which indicates that these three attitude variables did not influence the students' understanding of the measures of central tendency.

\section{DISCUSSION}

The study found that students' understanding of the measures of central tendency was situated within the moderate level. Overall, students were found to have a good understanding about the Definition regarding the measures of central tendency. However, there were many students who were unable to give the correct response for the item which assessed students' understanding of Definition for mode. This indicates that the students may not understand the mode concept, and are confused with the words mean, mode, and median. Watson and Moritz (2000)'s study also revealed that students experienced confusion with the words mean, mode, and median.

In the assessment of the Procedure of the measures of central tendency, the results revealed that students had not yet mastered the computation of the measures of central tendency in the frequency table, especially for mean (weighted mean) and median. The results of the study were consistent with the study of Pollatsek, Lima and Well (1981) who found students had errors in computing weighted mean. Meanwhile, instead of mean, students in Barr (1979)'s study were found having difficulty in finding mode and median from a frequency table. 
Regarding the Properties of the measures of central tendency, students' level of understanding was found to be low. The result indicated that most of the students did not understand the idea of robustness in the measures of central tendency, which implies that they still did not understand the effect of extreme value or outlier in the data. Besides that, students also did not understand which measures of central tendency could be used when the data was in quantitative as well as qualitative form. Similarly, Batanero et al. (2003) reported the students' poor responses regarding to the properties of mean.

Furthermore, based on the students' responses on the items which assessed their understanding of Problem and Representation construct, most of the students did not know that mean, median and mode are types of average. Besides that, a majority of the students also did not know how to choose which type of average as the best representative for the given data (whether the extreme value was present or not). This implies failure in understanding the concept of representative value for the measures of central tendency, as well as the extreme value or outlier concept. Zawojewski and Shaughnessy (2000) stated that students faced difficulties in choosing the appropriate measures of central tendency to best represent data sets. Meanwhile, Chatzivasileiou et al. (2010) in their study also found that in terms of representative concept, students failed to explain the data, which indicated the lack of conceptual understanding.

Similarly, students' understanding regarding the Argument and Proof construct were found to be very low. In this study, students were instructed to give their reasoning or justification for the reasons they chose a certain type of average (mean, median, and mode) as the best representative for the given data (whether the extreme value was present or not). However, the majority of the students failed to give the correct reasoning or justification for the answer. This was due to the students' falling short of understanding the representative and extreme value concept.

The result from descriptive analysis shows that students held an overall positive attitude towards statistics. The result was consistent with Carmona et al. (2005), Mahmud (2010), Ashaari et al. (2011), Naccache (2012), Zhang et al. (2012), Stanisavljevic et al. (2014) and Ghulami et al. (2015), but not consistent with Rosli and Maat (2017) and Rosli et al. (2017). In terms of components of students' attitudes towards statistics, the results revealed that the students felt positive in all components except for Value. Students held a more positive attitude in Effort, followed by Cognitive Competence, Interest, Difficulty, Affect, and Value. This indicated that students put great effort and worked hard to learn statistics to obtain a better achievement in this subject, besides believing in their cognitive ability to understand and learn statistics. Besides that, the students opined that statistics is a subject which is easy to understand, quickly learnt by most people, not complicated and not difficult to be learnt. Furthermore, it was revealed that the students held a high interest in statistics and thought that statistics is not a frightening and frustrating subject.

The result of the study was not consistent within the study of Ghulami et al. (2015) and Zhang et al. (2012), who stated that university students held a negative attitude towards statistics regarding the Difficulty component. The differences of the result might have occurred due to the students' different levels of education. Students in a higher level of education were exposed to more challenging, difficult, and complicated statistical concepts and formula than the students that are in the secondary school.

Generally, the study discovered that male students had an overall higher understanding of the measures of central tendency compared to the female students. With regard to the gender difference based on the constructs, it was revealed that the male students scored higher than the female students in all constructs, except for the Definition construct. Only Properties, Problem and Representation, and Procedure constructs showed a significant difference based on gender. The differences of students' understanding related to these constructs may be due to the other factors which are not being studied in this study, such as the differences in students' learning styles, learning strategies and teacher's instructional approach and materials.

As for the students' attitudes towards statistics, the result revealed that there was no significant difference in students' attitudes towards statistics based on gender. Besides that, no gender difference was found with respect to the components. The result of the study was not consistent with Chiesi and Primi (2016), where the female students showed more a negative attitude and were less confident learning statistics. According to the researchers, female students tend to underestimate their abilities and had more negative attitudes toward quantitative disciplines when compared to male students. Meanwhile, according to Araki (1995), the cultural treatment of men often encourages them to be more analytical thus statistics would seem less threatening than for women. In teaching statistics, this concern has to be taken into account since it may create an obstacle for learning. 
The results revealed that there were no significant and very weak negative relationships between students' understanding of the measures of central tendency and students' attitudes towards statistics. Of all the attitudes towards statistics components investigated, Effort was found to be negatively significant and weakly correlated with the students' understanding of the measures of central tendency. One interpretation of this is that students who employed a learning style that is strongly effort-based might not enable the student to gain more understanding about statistical concepts. This finding will have a strong impact on statistics education, where studying with great effort does not bear a good understanding of statistical concepts. In the case of statistical reasoning, Garfield (2002) in Templaar (2004) stated that the quality of learning with effort invested in it does not guarantee proper reasoning skills.

The results of the study suggested that the attitude of students about their intellectual knowledge and skills applied to statistics could influence their understanding of statistical concepts. The more positive the students are about their knowledge and skills applied to statistics, the better their understanding will be of statistical concepts. On the other hand, the study showed that students who willingly put a great effort to learn statistics do not necessarily have a good understanding of the measures of central tendency. According to Millar and Schau (2010), students whom show high effort were still unable to influence their achievement in statistics. This is because the students who were diligent could only affect the achievement if they had the appropriate learning techniques in their studies.

Besides that, the results of the study also suggest that the students' perception of the difficulty of statistics could impact their understanding of the measures of central tendency. In other words, students who struggled and had difficulty to learn statistics had a lower understanding of statistical concepts. Previous studies also revealed that the difficulty component could influence students' achievement in statistics (Cashin \& Elmore, 2005; Clark, 2010; Finney \& Schaw, 2003; Schau, 2003).

\section{CONCLUSION}

The present research fills the gap by assessing the level of Tenth Grade Science Stream students' understanding of the measures of central tendency and attitude towards statistics in rural secondary schools. Conclusively, students held a low level in their understanding on the properties, procedure, problem and representation, and argument and proof. Findings suggest that teachers should prioritize their intervention on enhancing comprehension of those statistical concepts among the students, besides finding out and understanding what steps should be taken when resolving a statistics problem. In addition, female students were found to have lower understanding of the measures of central tendency in Properties, Problem and Representation, and Procedure constructs as compared to male students. The research has therefore highlighted the pivotal role of applying appropriate instructional approaches and materials which could cater to the differences in male and female students' learning styles and learning strategies.

It is believed that this research has important implications for educators. This research will be able to provide mathematics educators an important indicator that the amount of effort students spends on learning statistics do not necessarily warrant a good understanding of the measures of central tendency. Specifically, it might be useful to introduce the appropriate learning technique in which students can realize that they can master the topic and develop better understanding in this discipline. This research involved only 148 Grade Ten students, and may not be representative of the Malaysian rural secondary school students and rural school students elsewhere in the world. Future research will therefore need to be carried out with a larger sample size. It would be useful to undertake further investigation on the extent to which factors could support students' effort in understanding statistical concepts. Educators also should consider the fact that there is a difference in students' learning styles and learning strategies. In addition, it would also be useful to investigate which of the instructional approaches and learning materials can improve students' understanding of statistical concepts, as well as their attitude towards statistics.

This research has also contributed substantive proof that mathematics or statistics educators need to be more aware of the students' learning experience in statistics lessons, and encourage them to find the most efficient way to learn statistics and overcome the difficulty in learning statistics. Thus, future researches might be conducted by collecting repeated measures of attitudes from the beginning to the end of the statistics lessons in order to monitor changes that might be due to the lessons themselves and specific activities implemented by the teachers. 


\section{Disclosure statement}

No potential conflict of interest was reported by the authors.

\section{Notes on contributors}

Siti Shahirah Saidi - Master of Science Eduation, PhD student, Faculty of Psychology and Education, Universiti Malaysia Sabah, Sabah, Malaysia.

Nyet Moi Siew - PhD, Senior Lecturer, Faculty of Psychology and Education, Universiti Malaysia Sabah, Sabah, Malaysia.

\section{REFERENCES}

Araki, L. (1995). An exploratory study of student attitudes toward statistics and their retention of statistical concepts (Master Thesis), Faculty of California State University, San Bernardino.

Ashaari, N. S., Judi, H. M., Mohamed, H., \& Tengku Wook, T. M. (2011). Students' Attitude towards Statistics Course. Procedia Social and Behavioral Sciences, 18, 287-94. https://doi.org/10.1016/j.sbspro.2011.05.041

Australian Bureau of Statistics. (n.d.). Statistical literacy. Retrieved on July 13, 2018 from http://www.statlit.org/pdf/2007ABS-Statistical_Literacy_Paper.pdf

Barr, G. V. (1979). Some student ideas on the median and the mode. Teaching Statistics, 2(2), 38-41. https://doi.org/10.1111/j.1467-9639.1980.tb00381.x

Batanero, C., Cobo Merino, B., \& Díaz, C. (2003). Assessing secondary school student's understanding of average. European Research in Mathematics Education III, 1-9.

Broers, N. J., \& Imbos, T. (2005). Charting and manipulating propositions as methods to promote selfexplanation in the study of statistics. Learning and Instruction, 15, 517-538. https://doi.org/10.1016/j.learninstruc.2005.08.005

Cai, J., \& Moyer, J. C. (1995). Middle school students' understanding of average: A problem solving approach. In D. T. Owens, M. K. Reed, and G. M. Millsaps (Eds.), Proceedings of the Seventeenth Annual Meeting of the North American Chapter of the International Group of the Psychology of Mathematics Education (Vol. 1, pp. 359-364). Columbus, OH: ERIC Clearinghouse for Science, Mathematics, and Environmental Education.

Carmona, J., Martinez, R. J., \& Sanchez, M. (2005). Mathematical background and attitudes toward statistics in a sample of Spanish college students. Psychological Reports, 97(1), 53-62. https://doi.org/10.2466/pr0.97.1.53-62

Cashin, S. E., \& Elmore, P. B. (2005). The Survey of Attitudes toward Statistics scale: A construct validity study. Educational and Psychological Measurement, 65(3), 509-524. https://doi.org/10.1177/0013164404272488

Chatzivasileiou, E., Michalis, I., \& Tsaliki, C. (2010). Elementary School Students' Understanding of Concept of Arithmetic Mean. In C. Reading (Ed.), Data and context in statistics education: Towards an evidencebased society. Proceedings of the Eighth International Conference on Teaching Statistics (ICOTS8), July, 2010, Ljubljana, Slovenia. Voorburg, The Netherlands: International Statistical Institute.

Chiesi, F., \&, Prim, C. (2015). Gender differences in attitudes toward statistics: Is there a case for a confidence gap? Konrad Krainer; Nad'a Vondrová. CERME 9 - Ninth Congress of the European Society for Research in Mathematics Education (pp.622-628). Feb 2015, Prague, Czech Republic. Proceedings of the Ninth Congress of the European Society for Research in Mathematics Education.

Chua, Y. J. (2009). Interrelationships Between Students' Attitudes Toward Mathematics, Beliefs About Mathematics Learning, Confidence in Solving Mathematical Problems and Mathematics Performance (Unpublished thesis), Universiti Malaysia Sarawak, Kuching, Sarawak

Clark, K. L. (2013). Undergraduate Students' Attitudes toward Statistics in an Introductory Statistics Class (Master Thesis). Clayton State University.

Curriculum Development (2012). Integrated Curriculum for Secondary Schools: Mathematics Form 4. Putrajaya: Malaysian Ministry of Education. 
Curriculum Development Division. (2011). Integrated Curriculum for Secondary Schools: Mathematics Form 3. Putrajaya: Malaysian Ministry of Education.

Curriculum Development Division. (2014). Standard Curriculum for primary schools: Mathematics Year 5. Putrajaya: Malaysian Ministry of Education.

Emmioglu, E., \& Capa-Aydin, Y. (2012). Attitudes and Achievement in Statistics: A Meta-Analysis Study. Statistics Education Research Journal, 11(2), 95-102.

Finney, S. J., \& Schaw, G. (2003). Self-efficacy beliefs in college statistics courses. Contemporary Educational Psychology, 28(2), 161-186. https://doi.org/10.1016/S0361-476X(02)00015-2

Garfield, J. B. (2002). The challenge of developing statistical reasoning. Journal of Statistics Education, 10(3), 1-12. https://doi.org/10.1080/10691898.2002.11910676

Garfield, J. B., \& Ben-Zvi, D. (2008). Research on teaching and learning statistics. In J. B. Garfield \& D. BenZvi (Eds.). Developing students'statistical reasoning: Connecting research and teaching practice (pp. 2143). Springer. https://doi.org/10.1007/978-1-4020-8383-9_2

Ghulami, H. R., Ab Hamid, M. R., \& Zakaria, R. (2015). Students' Attitudes towards Learning Statistics. AIP Conference Proceedings, 1660, 050035; doi: 10.1063/1.4915668. https://doi.org/10.1063/1.4915668

Godino, J. D., \& Batanero, C. (1997). Clarifying the meaning of mathematical objects as a priority area of research in Mathematics Education. In A. Sierpinska, \& J. Kilpatrick (Eds.). Mathematics Education as a Research Domain: A Search for Identity (pp. 177-195). Dordrecht: Kluwer,

Griffith, J. D., Adams, L. T., Gu, L. L., Hart, C. L., Nichols-Whitehead, P. (2012). Students' Attitudes toward Statistics Across the Disciplines: A Mixed-Methods Approach, Statistics Education Research Journal, 11(2), 45-56.

Ismail, Z., \& Shiau, W. C. (2015). Malaysian Students' Misconceptions about Measures of Central Tendency: An Error Analysis. AIP Conference Proceedings, 1643(1), 93-100. https://doi.org/10.1063/1.4907430

Judi, H. M., Ashaari, N. S., Mohamed, H., \& Wook, T. M. T. (2011). Students profile based on attitude towards statistics. Procedia Social and Behavioral Sciences, 18, 266-272. https://doi.org/10.1016/j.sbspro.2011.05.038

Krejcie, R. V., \& Morgan, D. W. (1970). Determining Sample Size for Research Activities. Educational and Psychological Measurement, 30, 607-610. https://doi.org/10.1177/001316447003000308

Liau, A. K., Kiat, J. E., \& Nie, Y. (2015). Undergraduate Students Investigating the Pedagogical Approaches Related to Changes in Attitudes Toward Statistics in a Quantitative Methods Course for Psychology Undergraduate Students. The Asia-Pacific Education Researcher, 24(2), 319-327. https://doi.org/10.1007/s40299-014-0182-5

Mahmud, Z. (2010). A discriminant analysis of perceived attitudes toward statistics and profile identification of statistics learners. Proceedings of the $2^{\text {nd }}$ WSEAS International Conference on Multivariate Analysis and its Application in Science and Engineering, pp.41-47.

Mahmud, Z., \& Zainol, M.S. (2008). Examining postgraduate students' perceived competency in statistical data analysis and their attitudes toward statistics. International Journal of Education and Information Technologies, 1, 79-86.

Martins, J., Nascimento, M., \& Estrada, A. (2011). Attitudes of teachers towards statistics: A preliminary study with Portuguese teachers. In Proceedings of Seventh Congress of the European Society for Research in Mathematics Education (CERME 7). Rzeszow, Poland: University of Rzeszow and ESRM. Retrieved from http://www.cerme7.univ.rzeszow.pl/WG/5/CERME_Martins-Nascimento-Estrada.pdf

Milic, N. M, Masic, S., Milin-Lazovic, J., Trajkovic, G., Bukumiric, Z., \& Savic, M. (2016). The Importance of Medical Students' Attitudes Regarding Cognitive Competence for Teaching Applied Statistics: MultiSite Study and Meta- Analysis. PLoS ONE, 11(10), e0164439. https://doi.org/10.1371/journal.pone.0164439

Millar, A. M., \& Schau, C. (2010). Assessing Students' Attitudes: The Good, the Bad, and the Ugly. Proceedings of the Joint Statistical Meetings. Retrieved from www.statlit.org/pdf/2010MillarSchauASA.pdf

Mohamad Judi, H., Ashaari, N.S., Mohamed, H., \& Tengku Wook, T.M. (2011). Students Profile Based on Attitude towards Statistics. Procedia Social and Behavioral Sciences, 18, 266-72. https://doi.org/10.1016/j.sbspro.2011.05.038

Naccache, H. S. (2012). Factors Related to Student Performance in Statistics Courses in Lebanon (Doctoral Thesis). The University of Southern Mississippi. 
Pollatsek, A., Lima, S., \& Well, A. D. (1981). "Concept or Computation: Students' Understanding of the Mean." Educational Studies in Mathematics, 12(2), 191-204. https://doi.org/10.1007/BF00305621

Ramsey, J. B. (1999). Why Do Students Find Statistics So Difficult? Proceedings of the $52^{\text {nd }}$ Session of the International Statistics Institute. Retrieved on August 10, 2018 from https://iaseweb.org/documents/papers/isi52/rams0070.pdf

Reston, E., Krishnan, S., \& Noraini Idris. (2014). Statistics Education Research in Malaysia and the Philippines: A Comparative Analysis. Statistics Education Research Journal, 13(2), $218-31$.

Rhoads, T. R., \& Hubele, N. F. (2000). Student attitudes toward statistics before and after a computerintegrated introductory statistics course. IEEE Transactions in Education, 43, 182-187. https://doi.org/10.1109/13.848071

Rosli, M. K., \& Maat, S. M. (2017). Attitude towards Statistics and Performance among Post-Graduate Students. AIP Conference Proceedings, 1847, 030004. https://doi.org/10.1063/1.4983881

Rosli, M. K., Maat, S. M., \& Rosli, R. (2017). Students' attitude and anxiety towards statistics: A descriptive analysis. Research on Education and Psychology, 1(1), 47-56.

Schau, C. (2003). Students' attitudes: The "other" important outcome in statistics education. Paper presented at the Joint Statistical Meetings, San Francisco, CA.

Schau, C., Millar, M., \& Petocz, P. (2012). Research on Attitude towards Statistics. Statistics Education Research Journal, 11(2), 2-5.

SDC (2011). Sabah Economic Development and Investment Authority Blueprint. Retrieved from http://www.sedia.com.my/

Singh, P., Abdul Rahman, A., \& Teoh, S. H. (2010). Languages and Mathematics Achievements among Rural and Urban Primary Four Pupils: A Malaysian Experience. Journal of Science and Mathematics, 33(1), $65-85$.

Stanisavljevic, D., Trajkovic, G., Marinkovic, J., Bukumiric, Z., Cirkovic, A., \& Milic, N. (2014). Assessing Attitudes towards Statistics among Medical Students Psychometric Properties of the Serbian Version of the Survey of Attitudes towards Statistics (SATS). PLOS ONE, 9(11). https://doi.org/10.1371/journal.pone.0112567

Tarmimi, A., \& Kadri, S. (2016). Tahap Kefahaman Dan Salah Konsep Terhadap Konsep Daya Dan Gerakan Dalam Kalangan Pelajar Tingkatan Empat. Jurnal Fizik Malaysia, 37(1), 1090-1101.

Tempelaar, D. (2004). Statistical Reasoning Assessment: An Analysis of the SRA Instrument. Proceedings of the ARTIST Roundtable Conference on Assessment in Statistics, Lawrence University.

Tempelaar, D. T., van Der Loeff, S. S., \& Gijselaers, W. H. (2007). A structural equation model analyzing the relationship of students' attitudes toward statistics, prior reasoning abilities and course performance. Statistics Education Journal, 6(2), 78-102.

Watson, J. M., \& Moritz, J. B. (2000). The longitudinal development of understanding of average. Mathematical Thinking and Learning, 2(1\&2), 11 - 50. https://doi.org/10.1207/S15327833MTL0202_2

Wisenbaker, J. M., Scott, J. S., \& Nasser, F. (2000, July/August). Structural equation models relating attitudes about and achievement in introductory statistics courses: A comparison of results from the U.S. and Israel. Paper presented at the 9th International Congress on Mathematics Education, Tokyo, Japan.

Woldemicheal, M. (2015). Enhancing Secondary Students' Understanding of Descriptive Statistics Using Contextual and Socio-critical Modeling: The Case of West Shewa Zone, Ethiopia (Doctoral Thesis). Addis Ababa University.

Zawojewski, J. S., \& Shaughnessy, J. M. (2000). Data and chance. In E.A. Silver and P.A. Kenney (Eds.), Results from the seventh mathematics assessment of the National Assessment of Educational Progress Reston (pp. 235-268). VA: National Council of Teachers of Mathematics.

Zhang, Y., Shang, L. Wang, R., Zhao, Q., Li, C., Xu, Y., \& Su, H., (2012). Attitudes toward Statistics in Medical Postgraduates: Measuring, Evaluating and Monitoring. BMC Medical Education, 12(117), 1-8. https://doi.org/10.1186/1472-6920-12-117 